\title{
PEMEKATAN SITRONELAL DALAM MINYAK SEREH WANGI (Cymbopogon Nardus L.) DENGAN FRAKSINASI DISTILASI DAN IDENTIFIKASI MENGGUNAKAN KG-SM
}

\author{
Marlia Ferdayanti, Prof. Hardjono Sastrohamidjojo dan Riyanto \\ Program Studi Ilmu Kimia, Fakultas Matematika dan Ilmu Pengetahuan Alam \\ Universitas Islam Indonesia \\ lifah_fy@yahoo.co.id
}

\section{INTISARI}

Telah dilakukan pemekatan sitronelal dalam minyak sereh wangi (Cymbopogon Nardus L.) dengan fraksinasi distilasi dan identifikasi menggunakan kromatografi gasspektrometri massa.

Dalam penelitian ini digunakan metode fraksinasi distilasi menggunakan minyak sereh wangi sebagai sampel dengan volume $250 \mathrm{ml}$, dan difraksinasi melalui tiga tahapan fraksinasi selama 2 jam pada tekanan $3 \mathrm{mmHg}$. Produk yang dihasilkan dianalisis menggunakan KG-SM. Hasil analisis KG-SM menunjukkan adanya senyawa sitronelal terbesar dihasilkan pada fraksi ke-1 yaitu sebesar 25,38 \% dengan temperatur fraksinasi sebesar $48-55.5^{\circ} \mathrm{C}$ diperoleh minyak sebanyak $76 \mathrm{~mL}$, indeks bias 1,4450 , putaran optik $\left(-1^{\circ}\right)$, bobot jenis $0,857 \mathrm{gr} / \mathrm{mL}$.

Kata kunci : minyak sereh wangi, sitronelal, distilasi fraksinasi

\section{PENDAHULUAN}

Minyak sereh wangi (Citronella oil) dari tanaman sereh wangi (Cymbopogon winterianus) merupakan salah satu jenis minyak atsiri yang sering juga disebut dengan minyak eteris atau minyak terbang karena kemampuannya yang mudah menguap dan memiliki komposisi serta titik didih yang berbeda-beda. Untuk menaikkan rendemen dari minyak sereh wangi dilakukan usaha dengan memperbaiki metode distilasi dan kondisi operasi agar proses penyulingan dapat menghasilkan minyak sereh wangi dengan standar mutu yang berlaku.

Pada penelitian ini digunakan sereh wangi karena adanya kandungan minyak atsiri inilah yang dapat menimbulkan aroma yang khas. Beberapa uraian tersebut, penulis ingin melakukan penelitian untuk mengetahui lebih spesifik akan komponen penyusun minyak atsiri pada minyak sereh wangi dalam tiap fraksi dengan cara fraksinasi distilasi, serta menentukan sifat fisika dan kimia pada minyak sereh wangi.

\section{Metodelogi Penelitian}

\section{Alat}

Seperangkat alat distilasi fraksinasi, Seperangkat alat-alat gelas, Kromatografi gas - spektroskopi massa, Piknometer, Refraktometer, Polarimeter.

\section{Bahan}

Minyak sereh (dari CEOS FMIPA UII), Aquades. 


\section{Prosedur Penelitian}

Minyak sereh sebanyak 250 $\mathrm{mL}$ disuling dengan menggunakan metode destilasi fraksinasi pengurangan tekanan selama 2 jam.Hasil distilasi kemudian ditampung. Minyak yang diperoleh ditimbang dan disimpan dalam tempat tertutup, kemudian dianalisis dengan GC-MS untuk mengetahui komponen-komponen penyusunnya.

Dari hasil fraksinasi maka ditentukan penetapan bobot jenis, putaran optik, indeks bias

\section{Analisis Kromatografi Gas- Spektroskopi Massa \\ Minyak yang telah diperoleh kemudian dianalisis dengan kromatografi gas-spektrometri massa untuk mengetahui komponen- komponen penyusunnya.}

\section{Hasil dan Pembahasan}

Sampel minyak sereh dari inventaris CEOS FMIPA UII, yang sebelumnya telah dianalisis KG-SM dimasukkan dalam labu alas bulat leher tiga sebanyak $250 \mathrm{ml}$ kemudian alat distilasi fraksinasi dirangkai yang kemudian dihubungkan dengan vakum yang diset awal pada titik didih dan tekanan $47-48^{\circ} \mathrm{C} / 3 \mathrm{mmHg}$, dimana pemasangan vakum bertujuan untuk menurunkan tekanan pada saat dilakukan proses distilasi sehingga senyawa akan menguap pada suhu dibawah titik didihnya. Hasil isolasi ini diperoleh minyak dengan tiga fraksi, sebagai berikut :
Tabel 1. Data Destilat Tiap Fraksi pada Distilasi Fraksinasi Sitronelal

\begin{tabular}{|c|c|c|c|}
\hline $\begin{array}{l}\text { Parameter } \\
\text { Pengukuran }\end{array}$ & $\begin{array}{c}\text { Fraksi } \\
\text { ke-1 } \\
\text { (F1) }\end{array}$ & $\begin{array}{c}\text { Fraksi } \\
\text { ke-2 } \\
\text { (F2) }\end{array}$ & $\begin{array}{c}\text { Fraksi } \\
\text { ke-3 } \\
\text { (F3) }\end{array}$ \\
\hline $\begin{array}{l}\text { Temperatur } \\
\left({ }^{\circ} \mathrm{C}\right)\end{array}$ & $48-55.5$ & $60-74$ & $80-96$ \\
\hline $\begin{array}{l}\text { Volume } \\
\text { (mL) }\end{array}$ & 76 & 58 & 112 \\
\hline $\begin{array}{l}\text { Indeks Bias } \\
\text { Putaran }\end{array}$ & 1.445 & 1.458 & 1.467 \\
\hline $\begin{array}{l}\text { Optik } \\
\text { Bobot Jenis }\end{array}$ & -1 & -1 & -1 \\
\hline $\begin{array}{l}\left(20^{\circ} \mathrm{C} / 20^{\circ} \mathrm{C}\right) \\
\text { Sitronelal } \\
(\%)\end{array}$ & $\begin{array}{l}0.857 \\
25,38\end{array}$ & $\begin{array}{r}0.853 \\
6,88\end{array}$ & 0.857 \\
\hline
\end{tabular}

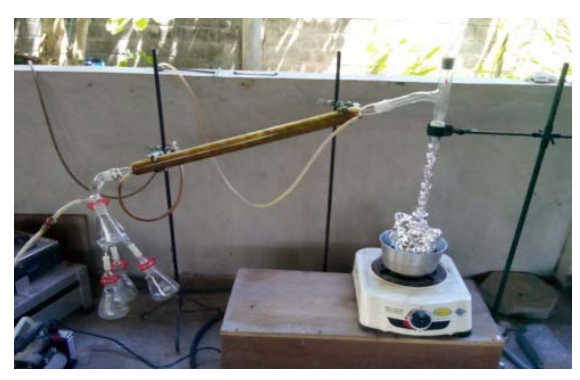

Gambar 1. Alat Fraksinasi Distilasi

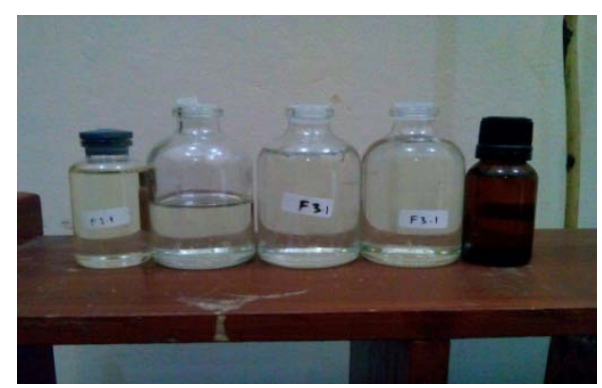

Gambar 2. Minyak Hasil Fraksinasi Distilasi

Minyak yang diperoleh tersebut kemudian dianalisis menggunakan Kromatografi GasSpektroskopi Massa serta uji kualitatifnya (indeks bias, bobot jenis, putaran optik). 
Identifikasi Minyak Sereh sebelum kromatografi gas seperti yang Fraksinasi ditunjukkan pada gambar berikut :

Berikut ini ditampilkan kromatogram dari identifikasi sampel minyak sereh menggunakan

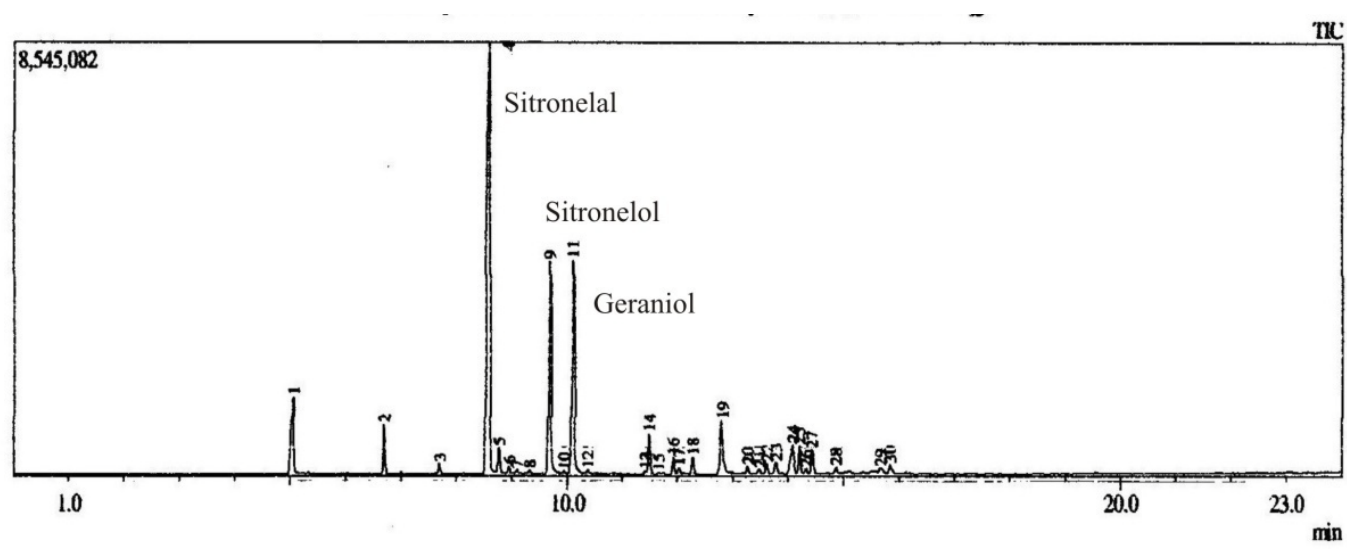

Gambar 3. Hasil Kromatogram Sampel Minyak Sereh Wangi

Setelah dianalisis dengan tersebut, 3 puncak memiliki kromatografi gas-Spektrometri massa konsentrasi tinggi. terdapat 30 puncak. Dari 30 puncak

Tabel 2. Daftar Komponen Penyusun Minyak Sereh

\begin{tabular}{|c|c|c|c|}
\hline Puncak & $\begin{array}{r}\text { Waktu } \\
\text { retensi }\end{array}$ & Konsentrasi & \\
\hline 4 & 8,584 & $38,12 \%$ & Sitronelal \\
\hline 9 & 9,688 & $14,84 \%$ & Sitronelol \\
\hline 11 & 10,110 & $15,32 \%$ & Geraniol \\
\hline
\end{tabular}

Identifikasi Minyak Sereh Setelah Fraksinasi

Sitronelal Fraksi ke-1 (F1) 


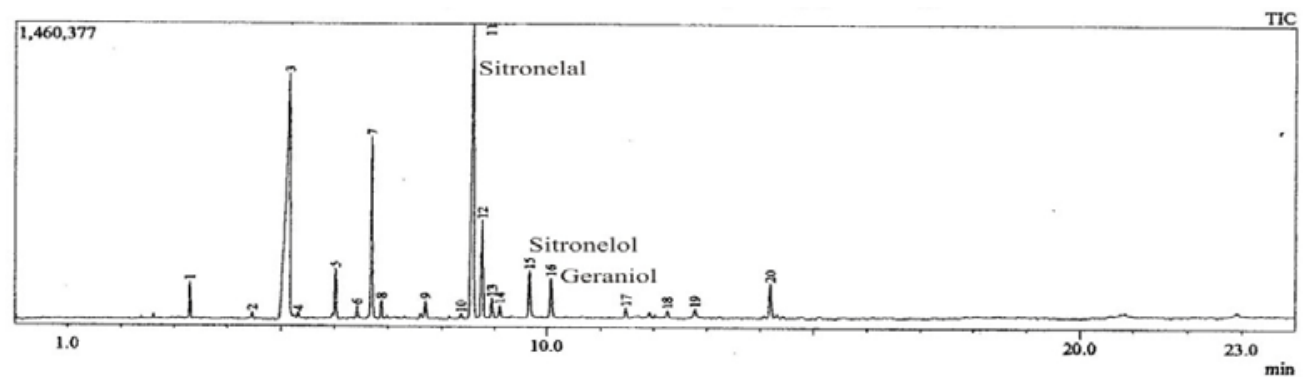

Gambar 7. Kromatogram Minyak Sereh Hasil Fraksi ke-1

Hit\#:3 Entry:43603 Library:WILEY7.LIB

SI:90 Formula:C10 III8 O CAS:106-23-0 MolWeight:154 RelIndex:0

CompName:CITRONELLA \$\$ 6-Octenal, 3,7-dimethyl- (CAS) Citronellal \$\$ Rhodinal \$\$ .beta.-Citronellal \$ 3,7-Dimethyl-6-octenal \$\$2,3-Dihydro

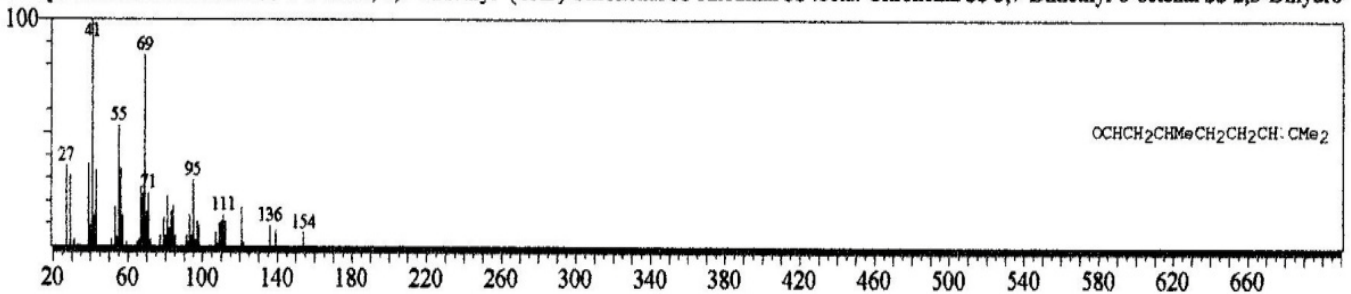

Gambar 8. Hasil Spektra Massa Sitronelal

Sitronelal Fraksi ke-2 (F2)

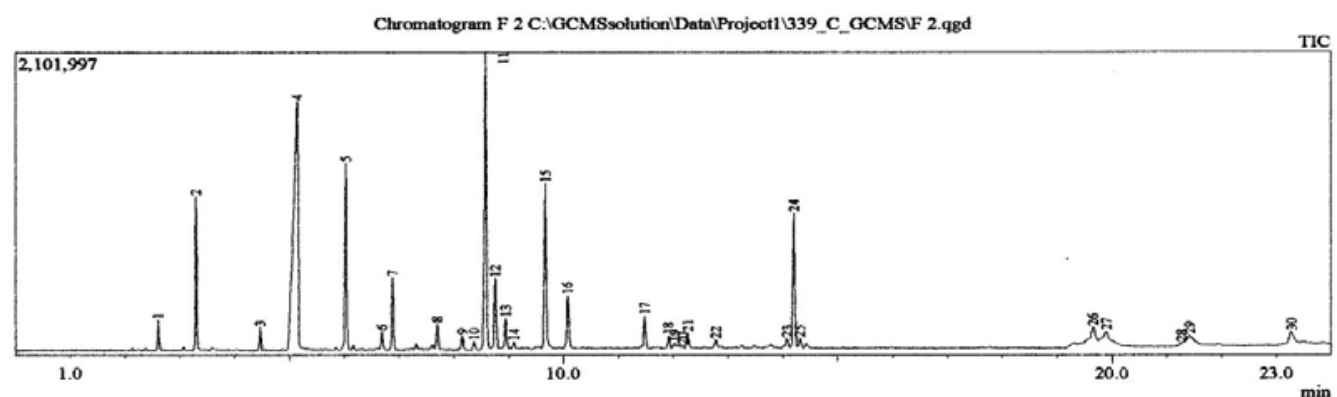

Gambar 9. Kromatogram Minyak Sereh Hasil Fraksi ke-2

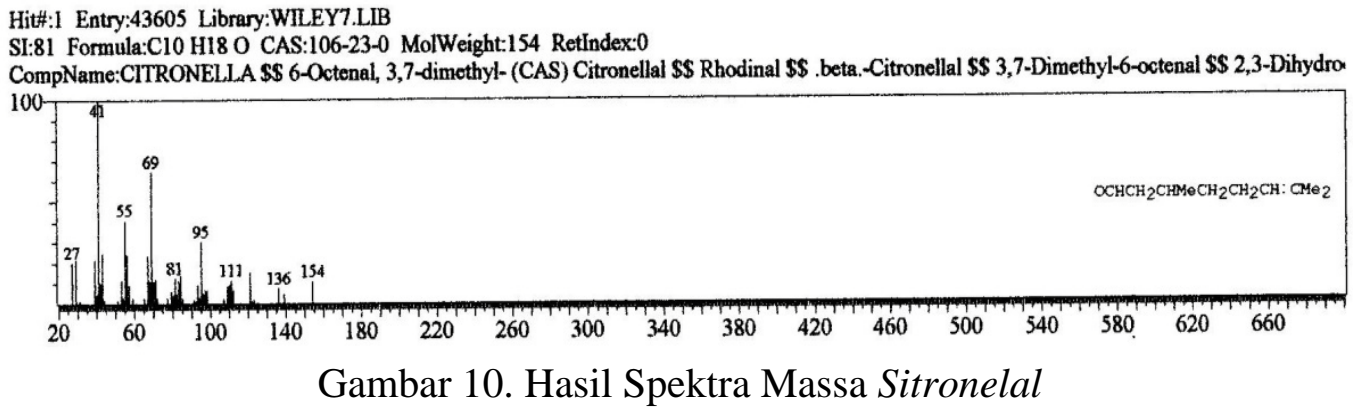


Sitronelal Fraksi ke-3 (F3)

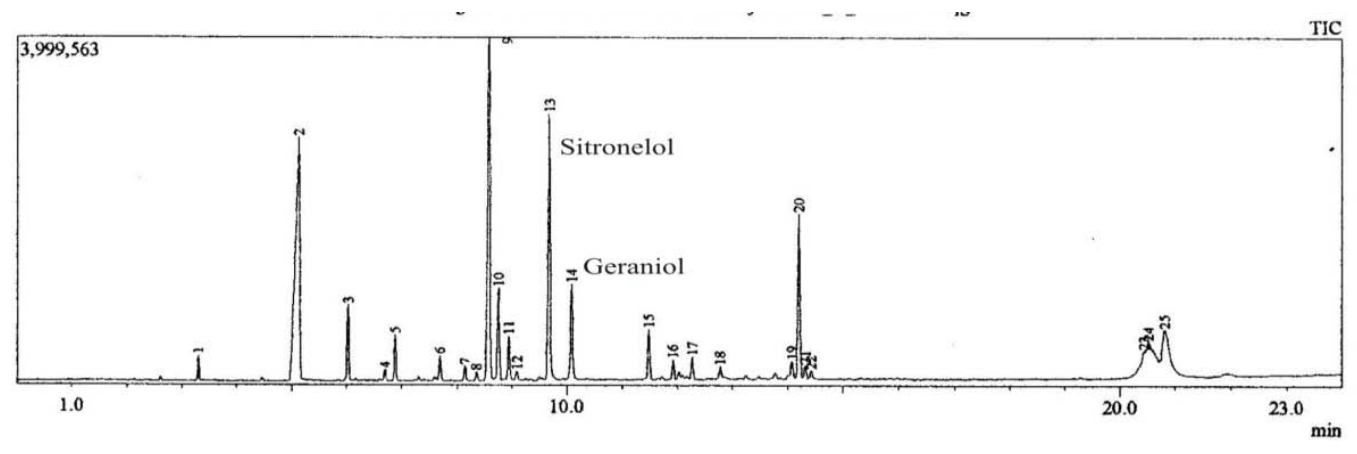

Gambar 11. Kromatogram Minyak Sereh Hasil Fraksi ke-3

\section{Analisis Kualitatif Sitronelal}

\section{Bobot jenis}

Pada minyak sereh ini diperoleh nilai berat jenis sitronelal fraksi ke-1 sebesar 0,857 $\mathrm{gr} / \mathrm{mL}$, fraksi ke-2 sebesar $0,853 \mathrm{gr} / \mathrm{mL}$, fraksi ke-3 sebesar 0,857 $\mathrm{gr} / \mathrm{mL}$. nilai ini sesuai dengan standar SNI yaitu 0,850 - 0,860, maka dapat dikatakan mutu dari minyak itu baik.

\section{Indeks bias}

Indeks bias untuk minyak sereh ini adalah fraksi ke-1 1,4450, fraksi ke-2 1,4520, fraksi ke-3 1,4530. nilai ini sesuai dengan standar yang diberikan oleh SNI yaitu berkisar antara 1,4440 1,4540 .

\section{Putaran optik}

Pada minyak sereh ini diperoleh nilai putaran optik untuk fraksi ke-1 sebesar $\left(-1^{\circ}\right)$, fraksi ke-2 sebesar $\left(-1^{\circ}\right)$, fraksi ke-3 sebesar ($\left.1^{\circ}\right)$. Nilai ini sesuai dengan standar nilai SNI yaitu berkisar antara $\left(-1^{\circ}\right)$ - $\left(+11^{\circ}\right)$. Maka dapat disimpulkan kualitas minyak ini baik.

\section{Kesimpulan}

Sitronelal merupakan komponen utama dari minyak sereh wangi yang dapat dipisahkan menggunakan fraksinasi distilasi.Pada fraksi ke-1 diperoleh kondisi optimum dengan tekanan 3 mmHg konsentrasi 25,38 \%, suhu $48^{\circ} \mathrm{C}-55,5^{\circ} \mathrm{C}$ dan jumlah distilat yang ditampung sebanyak 76 mL.Dari hasil uji kualitatif diperoleh indeks bias adalah F1 (1,4450), F2 $(1,4520)$, F3 $(1,4530)$. nilai ini sesuai dengan standar yang diberikan oleh SNI yaitu berkisar antara 1,4440 1,4540. Pada minyak sereh ini diperoleh nilai putaran optik sebesar : F1 $\left(-1^{\circ}\right)$, F2 $\left(-1^{\circ}\right)$, F3 $\left(-1^{\circ}\right)$. Nilai ini sesuai dengan standar nilai SNI yaitu berkisar antara $\left(-1^{\circ}\right)-\left(+11^{\circ}\right)$. Maka dapat disimpulkan kualitas minyak ini baik.Pada minyak sereh ini diperoleh nilai bobot jenis sebesar : F1 (0,857 gr/mL), F2 (0,853 gr/mL), 
F3 $(0,857 \mathrm{gr} / \mathrm{mL})$. nilai ini sesuai dengan standar SNI yaitu 0,850 -
0,860, maka dapat dikatakan mutu

dari minyak itu baik.

\section{Daftar Pustaka}

Anonim, 2007, Sereh. URL:http://www.iptek.net.id/pd tanobat/view.php/id. [02 September 2013].

Dewan Atsiri Indonesia dan IPB.2009. Minyak Atsiri Indonesia. http:///www.Minyak/Atsiri/Indonesia.html .[13 Oktober 2013].

Fahn, A, 1998, Anatomi Tumbuhan Edisi Ketiga.Gadjah Mada University, Yogyakarta.

Guenther, Ernest., 1950, The Essential Oils: Individual Essential Oils of The Plant Families vol. IV, Van Nostrand Company Inc., New York.

Guenther, Ernest., 2006, The Essential Oils Jilid I, Robert E Krieger Publishing Co Inc., New York.

Guenther, Ernest, 1990, “Minyak Atsiri, Jilid IV A”, (terjemahan, Ketaren, R. S. Dan R. Mulyono), UI Press, Jakarta,

Harris, R., 1994, Tanaman Minyak Atsiri, Penebar Swadaya, Jakarta.

Irna SI dan Ernayenti, 2007.Pengenalan Geraniol dan Sitronelol. J. Plantus.

Juitasiahaan, 2012, Isolasi Minyak Sereh, diambil dari : http://www.http://juitasiahaan.blogspot.com/. [10 Oktober 2013].

Kim, Kyu J, Kang CS, Lee JK, Kim YR, Han HY, Yun HK. 2005. Evaluation of repellency effect of two natural aroma mosquito repellent compounds, citronella and citronellol. J Entomol. 35 (2): 117-120.

Miftakhurohmah, R. Noveriza, dan A. Kardinan. 2008. Efektivitas formula minyak serai wangi terhadap pertumbuhan kapang asal buah merah dan sambiloto. Buletin Penelitian Tanaman Rempah dan Obat. 19: 138-144.

Miller J.A., dan Neuzel E.F., 1980, Modern Experimental Organic Chemistry, Western Washingthon.

Nakahara K, Alzoreky NS, Yodhihashi T, Nguyen HTT, Trakoontivakorn G. 2003, Chemical Composition and Antifungal Activity of Essential Oil from Cymbopogon nardus (Citronella grass). JARG 37 (4): 249 -252.

Nurmansyah.2010. Efektivitas Minyak Seraiwangi dan Fraksi Sitronellal terhadap Pertumbuhan Jamur Phytophthora palmivora Penyebab Penyakit Busuk Buah Kakao.Bul. Litro. Vol. 21 (1): 43-52

Pinardi T., Hery K., M. Yulianto. 2010. Pengaruh Larutan Sereh Wangi dan Daun Tembelekan Terhadap Daya Tolak Gigitan Nyamuk Aedes Aegypti.Jurnal Penelitian Kesehatan Suara Forikes Vol 1 (1): 2086 -3098

Pitojo S., Zumiati., 2003, Tanaman Bumbu dan Pewarna Nabati, CV. Aneka Ilmu, Semarang. 
Perry, R.H \& D. Green., 1994. Perry’s Chemical Engineering Handbook. Mc GrawHill Company, New York.

Sabini, D., 2006, Aplikasi Minyak Atsiri pada Produk Home Care dan Personal Care, Konferensi Nasional Minyak Atsiri 2006, Solo.

Samarasekara, R., K.S. kalhari, and I. S. Weerasinghe. 2006. Insecticidal activity of Essential Oil of Ceylon Cinnamomum and Cymbopogon species Musca domestica. J. Essent. Oil Research.Vol. 18.Allowed Publishing Corp.pp.352354.

Sastrohamidjojo, H., 2004, Kimia Minyak Atsiri, Gadjah Mada University Press, Yogyakarta.

Sastrohamidjojo, H. , 1985, Kromatografi, Liberty, Jogyakarta

Setyaningsih D, Hambali E, dan Nasution M., 2000. Aplikasi Minyak Sereh Wangi (Citronella Oil) dan geraniol dalam pembuatan skin lotion penolak nyamuk. $J$ Tek Ind Pert 7(3):97-103

Siallagan, J., 2001, Isolasi Sitronelal dari Minyak Sereh. Skripsi. Fakultas Matematika dan Ilmu Pengetahuan Alam, Universitas Cedrawasih, Papua.

Siallagan, J., 1999, Isolasi Sitronelal dari Minyak Sereh Wangi dan Mempelajari Reaksi-Reaksinya Terhadap $\mathrm{HCl}$ Pekat, $\mathrm{H}_{2} \mathrm{SO}_{4}$ Pekat, dan $\mathrm{H}_{2} \mathrm{SO}_{4}$ Encer Pada Suhu $5^{\circ} \mathrm{C}$, Tesis S -2 Program Pasca Sarjana, Universitas Gadjah Mada : tidak diterbitkan

Sigit HS, Koesharso FX, Hadi UK, Gunandi DJ, Soviana S, Wirawan IA, Chalindaputra M, Rivai M, Priyambodo S, Yusuf S, Utomo S. 2006. Hama Pemukiman Indonesia: Pengenalan, Biologi dan Pengendalian. SH Sigit dan UK Hadi Editor. Bogor: Unit Kajian Pengendalian Hama Pemukiman. Fakultas Kedokteran Hewan. Institut Pertanian Bogor.

SNI. 1995. Standar Nasional Indonesia Minyak Sereh Wangi. Badan Standarisasi Nasional, Jakarta.

Utomo, H.P. dan Widiatmoko, N., 2009, Isolasi Rhodinol dalam Ekstraksi Minyak Sereh Jawa, Makalah Penelitian, Fakultas Teknik, Universitas Diponegoro, Semarang. 